\title{
Reflexiones sobre el Mitch La batalla de la verdad y de la compasión
}

Antes de reflexionar sobre la tragedia que ocasionó Mitch quisiera decir dos cosas que me parecen importantes. La primera es que, probablemente, no voy a decir nada nuevo. En efecto, ya se ha escrito mucho y bien sobre el Mitch. Y la razón fundamental para ello es, pienso yo, que el Mitch ofrece en sí mismo una gran transparencia: su realidad y sus consecuencias son inocultables, y a nada que se lo analice también es inocultable su significado. Y es que una tragedia de esa magnitud suele convertir los corazones de piedra en corazones de carne, mueve a la compasión y a la misericordia. Y esa conversión suele llevar a otra, bien difícil por cierto: a despertar a la verdad del mundo en que vivimos, a recibir ojos limpios para ver la verdad de las cosas. Y entonces, como dicen las bienaventuranzas, "los limpios de corazón verán a Dios", o -añadamos más modestamente- "verán la verdad de la realidad".

La segunda es que hablaremos sobre el Mitch y sus consecuencias, pero dejando en claro que la mayoría de nosotros no hemos padecido en carne propia la muerte ocasionada por el Mitch. Hablamos, pues, de vistas y de oídas; no hemos cargado con él. Esto no quita que no podamos y debamos reflexionar, analizar sus causas y consecuencias, y por supuesto, que no nos dejemos afectar por la exigencia e invitación a la solidaridad. Pero no hay que invertir los términos: los realmente experlos en el Mitch (así como en la deuda externa, en las atrocidades y burlas de todos los Pinochets, en los agravios de dictaduras e imperialismos) no somos, simplemente, "nosotros", sino las víctimas. Dicho esto, hagamos brevemente algunas constataciones y reflexiones.

\section{El Mitch es una inmensa tragedia "real"}

La combinación de las fuerzas de la naturaleza y la escasez de recursos históricos (más su uso deficiente) han producido en Centroamérica unos 20,000 muertos y desaparecidos, y dos millones y medio de damnificados. Existe, pues, el sufrimiento y la muerte masiva y cruel. Con ello, el Mitch no hace sino añadir sufrimiento "visible, estridente y espectacular" al sufrimiento fundamental, invisible, callado y cotidiano de los tres a cuatro mil millones de pobres y de los 1,300 millones de seres humanos que tienen que vivir con un dólar al día, lo cual para don Pedro Casaldáliga es la "macroblasfemia" de nuestro tiempo.

Esa tragedia produce varias reacciones. Una de ellas, aunque ahora no acaezca con frecuencia, es la de dirigirse a Dios como en la antigua teodicea: "Señor, ¿por qué?". O en las palabras de Jesús: "Dios mío, Dios mío, ¿por qué me has abandonado?" (y dicen los exegetas que éste es el único texto donde Jesús no se dirige a Dios llamándolo Abba, Padre). Y empezamos por aquí, porque recoger el grito que el ser humano lanza a Dios, cuando aquél se encuentra indefenso ante lo doloroso, aniquilador y absurdo, me parece importante para insistir en la realidad de las cosas, tanto de nuestro mundo y de nuestra historia como la de Dios. Si ambas realidades permanecen separadas y no referibles la una a la otra, Dios quedará en las nubes. Sin algo de teodicea, dudo mucho que tomemos a Dios en serio.

La otra reacción fundamental es protestar contra el olvido del "peso de lo real", lo cual ocurre con frecuencia. Ese olvido no ocurre ni puede ocu- 
rrir, por supuesto, en forma total, pues esa realidad "que pesa" asoma de muchas formas. Pero me parece que la actual intención de globalizar la realidad está basada -culturalmente - en otros presupuestos: parece ser real lo que no pesa: música, fútbol, deporte, entretenimiento y diversión... Todo el mundo sabe que las cosas no son así, que existen cosas que pensan mucho... Pero, tal como nos presentan la realidad, el Mitch y el sufrimiento humano que conlleva parecen disfuncionales. En mi opinión, aunque el remedio para la enfermedad del olvido ha sido duro, bueno es que el Mitch nos lleve a cuestionarnos sobre la realidad fundamental de este mundo: si es tal como nos lo describen e imponen los que están arriba, comenzando por Naciones Unidas, Banco Mundial, Grupo de los Siete, o si es la que asoma en una campesina hondureña huyendo de riadas, con dos niños en sus manos y cargando sobre su cabeza todo lo que tiene...

\section{El Mitch es una radiografía de la "familia humana"}

Dicen los antropólogos que los cementerios, la ciudad de los muertos con sus panteones vistosos y nichos apenas perceptibles, reflejan la ciudad de los vivos, con sus mansiones y sus champas. Pues bien, lo mismo ocurre con las catástrofes naturales (y también con las catástrofes históricas: en Vietnam, del ejército de Estados Unidos murieron, proporcionalmente, muchos más soldados portorriqueños y negros que soldados blancos).

Lo que el Mitch ha mostrado una vez más es que los que mueren, los que sufren y los que pierden son los de siempre. Se podrá argumentar - con razón en parte - que al campesinado centroamericano por razones culturales y de tradición le cuesta construir sus casitas algo elevadas, de modo que puedan protegerse un poco de las riadas. Pero el problema es más de fondo. Ante inundaciones y tcrremotos, las construcciones de los pobres son infinitamente más vulnerables que las de los ricos - y dígase lo mismo de las posibilidades de encontrar refugios y, sobre todo, de reconstruir lo destruido y recuperar lo perdido...

Esto, de puro evidente, es aceptado sin más. Se presenta como lo que pertenece a la naturaleza, no como producto de la historia. Al Mitch le competiría "por naturaleza" destruir las casas de los pobres y respetar las de los ricos. ( $\mathrm{Y}$ hay que añadir que cuando los huracanes azotan el sur de Estados
Unidos, aunque la destrucción sea grande siempre hay recursos a disposición de los ciudadanos estadounidenses para volver en poco tiempo a su situación anterior).

Como sabiamente han dicho nuestros mayores de la teología de la liberación, la verdad se ve mejor desde abajo y a veces sólo desde abajo, "desde el reverso de la historia", que decía Gustavo Gutiérrez, "desde el siervo sufriente", que decía Ignacio Ellacuría. Sinceramente, ante el Mitch y catástrofes similares no veo que las instituciones mundiales se hagan en serio estas reflexiones. ¿Por qué, cuando se juntan jefes de gobierno, miembros de Naciones Unidas, no se hace tema central el recurrente escándalo de que las catástrofes hunden a unos en la miseria total y a otros prácticamente no les afecta $-\mathrm{y}$ eso a nivel de personas y de pueblos? ¿Por qué no aprovechar estas ocasiones, aunque trágicas, para hacer las preguntas más fundamentales de nuestra actual humanidad como es "por qué unos viven y otros no"? Y si para esta pregunta no hay respuesta, si, peor aún, ni siquiera se plantea en serio, entonces, ¿qué hacemos en este mundo Iglesias, universidades, partidos políticos, gobiernos, ejércitos, Grupos de los Siete, Naciones Unidas, investigadores $\mathrm{e}$ inventores, artistas y deportistas...?

\section{El Mitch ha generado una solidaridad des-} conocida, que "hace soñar"

La gente de El Salvador, mayoritariamente pobre, se ha volcado a ayudar, $y$, aunque no somos expertos en el tema, parece cierto que la solidaridad que ha desencadenado el Mitch es generosa y desconocida, sobre todo en España. Oyendo Radio Exterior escuché que en un día se habían recogido diez millones de dólares en iniciativas personales y privadas. Escribí entonces que esas cosas "hacen soñar". El corazón humano, que tiende al distanciamiento, al egoísmo, al endurecimiento, puede volver a lo mejor suyo, a la compasión y la misericordia, al "corazón de carne" con que Dios lo dotó.

Por lo que he podido captar desde El Salvador, esta irrupción de la generosidad ha sido genuinamente espontánea, y no ha estado al servicio de segundas intenciones. Por lo que yo sé, no ha surgido "en nombre de la democracia", ciertamente no en nombre del neoliberalismo y la globalización", ni siquiera — si se me entiende bien- "en nombre de la religión o del cristianismo". La compasión 
ha brotado de lo mejor que somos y tenemos, de la compasión y de la misericordia. Y esto me parece importante, porque es la misericordia de la que habla Jesús en la genial parábola del buen samaritano: por el mero hecho de encontrarse con una víctima, aquel samaritano la auxilió. Jesús cuenta la párabola para explicar en qué consiste el amor al prójimo, pero al contarla no dice que el samaritano actuó para cumplir un mandamiento -el mayor de ellos, junto con el amor a Dios-, sino "movido a compasión". Nada hay, pues, más allá ni más acá de la misericordia. Y desde ella describen los

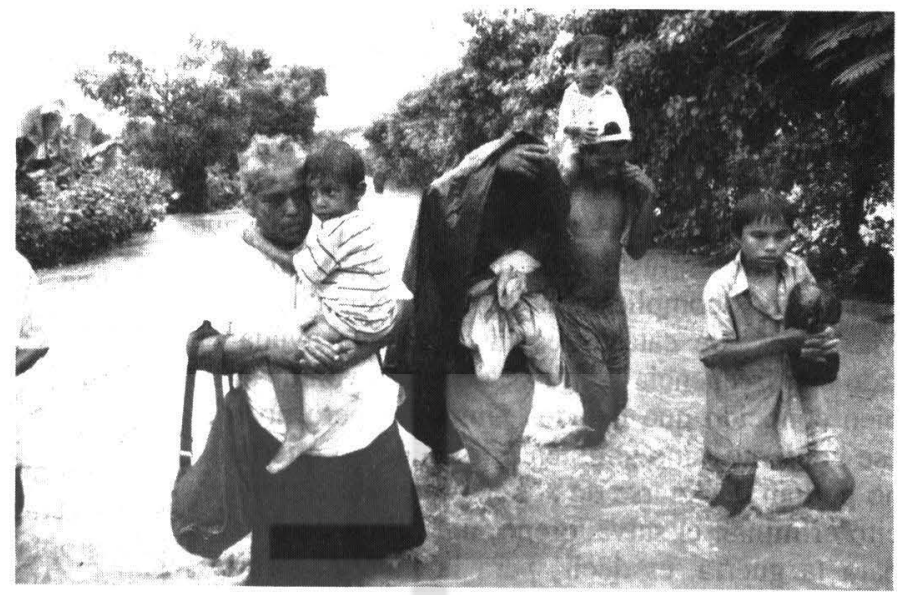
evangelios a Jesús: misereor super turbas, tengo compasión de cstas gentes. Y desde ella describe Jesús al ser humano cabal (el buen samaritano) y al mismo Dios, al Padre celestial, que movido a misericordia abrazó al hijo pródigo cabizbajo y avergonzado.

Quisicra, pues, valorar grandemente la generosidad que se ha desencadenado estos días hacia Centroamérica. Y me gustaría pensar también - aunque no sé si es así- que esa solidaridad generosa estaba preparada, al menos inconscientemente, porque en la década de los ochenta en España se hizo muy presente la Centroamérica doliente y crucificada. Tras la generosidad actual - pensamos- está el rostro desfigurado del siervo sufriente centroamericano: el rostro de Monseñor Romero, de las religiosas norteamericanas, de Ignacio Ellacuría y los suyos, $y$ de tantos y tantas que, aunque han quedado sin nombre, de alguna forma han quedado vivos en la conciencia colectiva de los pueblos de España.

\section{Ojalá la ayuda generosa se convierta en "so- lidaridad sostenible"}

El comentario es obligado. Los seres humanos lo podemos estropear todo, aun las cosas más nobles. Como ocurre siempre, ya ha habido limitaciones en la ayuda, ırampas y corrupción —no sé si mucha o poca- a altos niveles, politización de la ayuda... Pero nos queremos fijar en algunas cosas más importantes que tocan a lo esencial de la solidaridad.

La ayuda es buena y absolutamente necesaria, ciertamente en estos casos. Pero también hay que

estar claros en que puede terminar convirtiéndose en una limosna magnificada, en la que se ha dado algo de lo que uno tiene, pero sólo eso y nada más. Algunos, aunque sea poco, habrán dado de lo que necesitan, pero otros habrán dado de lo que les sobra - que sí es mucho. La solidaridad, sin embargo, vá más allá de la ayuda y de la limosna. Es un compromiso en el que se da de lo que uno tiene, pero, sobre todo, lo que uno es. Y, por ello, es una forma de vida.

Hace años, después de los asesinatos de la UCA, participé en San Francisco en un seminario sobre solidaridad. Recuerdo muy bien lo que dijo una joven que Irabajaba en solidaridad con El Salvador: "Solidarity? Forever”. "¿Solidaridad? Para siempre". Por eso no estará de más hablar no sólo de economía y crecimiento sostenible, sino también, y con mayor prioridad, de "compasión y solidaridad sostenible", no sólo ocasional.

Además, solidaridad es dar y recibir. Ojalá que los que tienen medios y han ayudado (españoles, europeos, norteamericanos...), hayan recibido algo importante de hombres y mujeres hondureñas -que no tienen nada-, aunque no sea más que la voluntad y la esperanza de vivir. Estos pueblos pobres ofrecen al primer mundo la "austeridad" como utopía y la "comunidad" como un modo de sobrevivir y, simplemente, de vivir humanamente. Sin saberlo, ponen al mundo en aquella "civilización de la pobreza", que Ellacuría veía como única łalvación para un mundo deshumanizado y deshurnanizante. En este sentido, lo que da el primer mundo no es más que devolver - "pagar", si se quiere- en ayuda material, ojalá también en ayuda del espíritu, lo 
que los pobres le ofrecen en forma de esperanza, comunidad, fe... Y no serían desdeñables "tratados comerciales" de este tipo.

Quiero recordar también, aunque es bien conocido, que ante catástrofes naturales se mueve el corazón de los humanos mucho más fácilmente que ante catástrofes históricas, quizás porque aquéllas traen menos complicaciones y conflictos que éstas. Más aún, ante catástrofes históricas, la ayuda ha sido con frecuencia criminal y en gran volumen. Es bien conocido que Estados Unidos - pero no sólo ese gobierno, sino también otros, que no querían o no podían desligarse de aquél- enviaba a un ejército criminal, el salvadoreño, un millón de dólares para la guerra, es decir, para la muerte, torturas, masacres, destrucción; también para la difamación, la calumnia, la mentira, el perjurio... Y también es verdad que otras instituciones, sobre todo no gubernamentales, enviaban ayuda para la población civil, los derechos humanos (además de ayuda militar para la guerrilla a veces). Pero volvamos al gobierno de Estados Unidos. Sea cual fuere su ayuda ahora ante el Mitch, no hay comparación con lo invertido entonces en toda el área centroamericana: ejércitos, aeropuertos, logística, entrenamiento, propaganda, Escuela de las Américas... Ojalá el Mitch - utopía- los haga recapacitar y confesar que su ayuda de entonces fue criminal (como la comunidad internacional está forzando ahora a Pinochet a reconocer sus crímenes) y los haga reflexionar sobre sus responsabilidades humanas y de gran potencial hacia los países pobres.

Por último, hay que estar en guardia de no caer, sutil o burdamente, en lo que denunciaba Jesús "se hacen llamar bienechores". Al menos por lo que toca a Centroamérica, la ayuda debe ser dada con humildad, no con prepotencia; con arrepentimiento, no con arrogancia. No se dice esto para aguar la fiesta de la solidaridad, sino para que ésta crezca, sea más y mejor.

\section{Reconstruir Centroamérica como modo de "revertir la historia"}

Existen ahora muchas iniciativas de la comunidad internacional para reconstruir Centroamérica y ojalá funcionen. El problema, que es teórico y práctico, consiste en qué se entiende por "reconstrucción". Puede entenderse, simplemente, como rehacer lo destruido. De esta manera volveremos a lo de antes, es decir, a lo de siempre, y seguiremos aceptando el mundo tal cual es, con toda su pobreza, su crueldad, su indignidad. Pero por reconstrucción puede comprenderse "crear algo nuevo". Aunque sea en pequeño, en Centroamérica se puede experimentar cómo hacer funcionar de manera muy distinta a la de hasta ahora a gobiernos, la banca, la empresa, ejércitos, universidades..., y también sindicatos, comunidades, movimientos populares. Puede experimentarse cómo decir la verdad de nuestro mundo y tomarla en serio. Eso sería no sólo rehacer lo dañado, sino construir una Centroamérica nueva, revertir la historia. $Y$ ahora que estamos todavía en época navideña, eso sería la utopía cristiana; la "nueva" tierra y el "nuevo" cielo. No los de antes, aunque ahora nos ayuden a remendarlos un poco. Por esto hay que trabajar y batallar, como hemos titulado este comentario.

$Y$ navidad nos puede ayudar en la batalla. A fin de cuentas nos dice grandes verdades, parecidas a las que ha puesto de manifiesto el Mitch. La primera gran verdad es que Jesús nació en la realidad más real, en una cueva de Belén y no junto al templo de Jerusalén. Al recordar hoy la pobreza de Belén, no se trata principalmente de fomentar una espiritualidad o una ascesis, sino de mencionar la realidad más real de nuestro mundo actual. Estamos acostumbrados a pensar que el nacimiento de Jesús en la pobre Belén expresaría la condescendencia inigualable de Dios, como si Dios hubiese hecho una formidable excepción al nacer en un pesebre para mostrar su gran amor hacia nosotros. Pero no es así. Belén no es la excepción, sino que es lo normal en nuestro planeta llamado Tierra. Navidad, como el Mitch, como la realidad de los informes anuales del PNUD, apunta a la realidad de nuestro mundo.

La segunda gran verdad es que el niño creció y en él se mostró lo realmente humano, lo que necesitamos para dar las batallas mencionadas. Dicho en breve, en Jesús lo humano apareció como honradez y verdad, anunciando a unos la buena nueva y denunciando a los que acaparan la vida para sf́. Apareció lo humano como compasión, misericordia y justicia, como el buen samaritano, cuyas entrañas se remueven y le llevan a actuar para sanar a las víctimas del camino. Apareció lo humano como fidelidad hasta el final, caminando entre el gozo de que "los pequeños han entendido a Dios" y "el llanto y los gemidos ante Dios" en el huerto de los Olivos. Apareció lo humano como entrega 
de la vida, dando de sí y dándose a sí mismo. Por último, lo humano apareció como solidaridad y fraternidad: "Jesús no se avergüenza de llamar hermanos" a los demás hombres y mujeres, como dice bellamente la Carta a los Hebreos.

Para revertir la historia contamos con Jesús y, por ello, con Navidad. Hay que luchar contra el consumismo, que en nada está interesado en nuevos cielos y nueva tierra. Hay que luchar contra el pragmatismo, que en nada aprecia lo que hay de gratuidad y de esperanza en Navidad. Pero ni el consumismo ni el pragmatismo tienen por qué tener la última palabra. La verdad, la solidaridad y la benignidad que han aparecido estos días de Mitch son una muestra, pequeña, pero real, de que es posible revertir la historia -0 empezar a dar algunos pasos.
Jon Sobrino

San Salvador, diciembre de 1998. 